\title{
A Narrative Review of Current Understanding and Classification of Dry Eye Disease with New Insights on the Impact of Dry Eye during the COVID- 19 Pandemic
}

\author{
Stefano Barabino
}

Received: May 11, 2021 / Accepted: July 1, 2021 / Published online: July 17, 2021

(C) The Author(s) 2021

\section{ABSTRACT}

Dry eye disease (DED) is a complex, progressive and multifactorial condition that is commonly seen in clinical practice and can be challenging to accurately diagnose. Untreated or suboptimally managed dry eye can progress to severe, chronic disease which may become resistant to treatment. Symptoms include ocular irritation and visual impairment. Patients frequently report negative consequences regarding quality of life (QoL), productivity and psychological wellbeing. Certain lifestyle factors (e.g. use of screen-based devices, air conditioning) can induce or exacerbate symptoms of DED, leading to progressive and debilitating complications. Exposures to such triggers are likely to have increased significantly during the ongoing COVID-19 pandemic with people across the

S. Barabino $(\bowtie)$

Centro Superficie Oculare e Occhio Secco, ASST

Fatebenefratelli-Sacco, Ospedale L. Sacco, Università

di Milano, via G.B. Grassi 74, 20157 Milan, Italy

e-mail: stebarabi@gmail.com globe living with heightened levels of stress/ anxiety while being forced to adapt most aspects of their daily lives (from work and education through to social activities) to accommodate social distancing, primarily through the use digital technologies. This review aims to provide a concise and practical overview of current understanding regarding DED, highlighting proposals for refined diagnostic categories and therapeutic terminologies that are designed to improve identification and management of dry eye as well as reduce or slow disease progression. Finally, the findings of a European survey are shared to illustrate the impact of the COVID-19 pandemic on the lives of people with DED. The survey was conducted during the first lockdown period (March-September 2020) and explored issues relating to psychological wellbeing, QoL and engagement with healthcare services. The results demonstrate the ways in which the pandemic amplified the impact of dry eye on daily life and may be valuable in enhancing understanding among clinicians of the challenges faced by people with DED, which extend beyond the signs and symptoms of disease.

Keywords: COVID-19; Dry eye disease; Inflammation; Ocular surface; Tear film homeostasis 


\section{Key Summary Points}

Dry eye disease (DED) is a common and multifactorial condition, characterised by a vicious circle of tear film instability and hyperosmolarity, that may be challenging to effectively diagnose and manage in clinical practice.

New proposals for refined diagnostic categories and therapeutic terminologies aim to improve identification and grading of DED severity and simplify approaches to treatment so that progressive complications may be reduced or avoided.

Symptoms of dry eye (e.g. ocular irritation, blurred vision) frequently impact quality of life (QoL) and psychological wellbeing, and exacerbations are often linked to lifestyle factors, with exposure to such triggers (e.g. use of screen-based devices) increasing for many during the ongoing global COVID-19 pandemic.

An online survey, conducted among 502 adults living with DED, provided context regarding the impact of the disease during the first COVID lockdown periodrevealing that dry eye had negatively impacted QoL for $72 \%$ of individuals, with increasing screen time (59\%), stress levels (50\%) and sleep disturbance (43\%) cited as reasons for worsening symptoms.

Productivity was affected because of DED symptoms (15\% had reduced ability to work and $10 \%$ were unable to work) and most $(62 \%)$ did not consult a clinician, despite feeling that they should, while the number choosing not to collect medications was significantly increased $(p<0.05)$.

\section{INTRODUCTION}

Dry eye disease (DED), also known as keratoconjunctivitis sicca or keratitis sicca, is a commonly encountered condition in clinical practice that is usually associated with symptoms such as ocular irritation and impaired vision as well as stinging, burning or scratching sensations [1]. Ocular pain can occur when neuropathic mechanisms are associated with DED [1]. Prevalence of DED is believed to range between $5 \%$ and $50 \%$ and susceptibility tends to increase with age $[2,3]$. Onset and exacerbation of symptoms may be associated with multiple factors including hormonal changes (e.g. menopause), autoimmune disease (e.g. Sjögren's syndrome), gender, use of topical and systemic medications, advancing age, environmental or lifestyle factors (e.g. air conditioning, use of screen-based technologies), allergies and the wearing of contact lens [4-8].

DED can significantly affect an individual's ability to undertake daily tasks and may negatively influence their quality of life (QoL) via multifaceted channels relating to reduced quality of vision and/or the development of psychological issues such as anxiety and depression [9, 10]. In addition, the economic burden of dry eye-related productivity loss is becoming increasingly apparent with absenteeism (absence from work) and presenteeism (attendance at work when unable to function effectively) due to symptoms of DED estimated to cost $\$ 11,302$ per person in the USA alone $[5,6,9,10]$. Healthcare costs associated with DED vary considerably across countries, although estimates regarding therapeutic expenditure are complicated by the widespread use of over-the-counter (OTC) therapies, which are frequently purchased by people seeking symptom relief [6].

This article aims to provide a concise and practical overview of current understanding in the field of DED, including aspects that may be helpful to clinicians when diagnosing and treating this common condition. New suggestions for the categorisation of disease severity are shared as well as consensus recommendations from an expert panel regarding the 
terminology used for different types of tear substitute. Finally, the growing significance of this condition as a consequence of modern lifestyle is discussed and illustrated through insights gleaned from an online European survey that examined the impact of dry eye on daily life during the initial wave of the SARSCoV-2 (COVID-19) pandemic. This article is based on previously conducted clinical studies and does not contain any new studies with human participants or animals performed by the author.

\section{DEFINING FEATURES OF DRY EYE}

DED has been defined according to the Tear Film Ocular Surface Society (TFOS) Dry Eye Workshop (DEWS) II as a multifactorial disease of the ocular surface characterised by a vicious circle of tear film instability and hyperosmolarity $[2,5]$. Disruption of ocular surface homeostasis causes inflammation, damage and neurosensory abnormalities [2, 3, 11-13]. Permanent ocular surface damage can occur if DED is allowed to progress without treatment [13].

The TFOS DEWS II criteria categorise DED as either aqueous deficient or evaporative dry eye [2]. Underproduction of tears results in the development of aqueous deficient dry eye, while meibomian gland dysfunction (MGD) is a key underlying cause of evaporative DED [2]. In practice, the majority of people will display signs and symptoms that relate to both types of disease [14]. DED is a progressive condition and patients benefit from timely diagnosis and treatment as more severe disease can become chronic and difficult to treat [13, 15]. Although the DEWS II criteria are helpful in highlighting the multifactorial nature of DED, diagnosis remains complex and challenging in daily practice. Unfortunately, DED often remains unrecognised until symptoms are significantly advanced [13, 15].

A recent consensus publication, reporting the recommendations of an expert panel of clinicians based in Italy, proposed a refined set of diagnostic categories for DED that defined three types of disease according to ascending pathological severity, reversibility and impact on visual disturbance [16]. Nominal group technique (NGT) and the Delphi method were used to reach a consensus on the features that were relevant to each DED type and Table 1 provides a summary of the new definitions proposed by the panel [16]. Type I refers to transient/mild DED, type II is a recurrent/moderate form of disease and type III defines chronic/severe dry eye [16]. The level of inflammation at the ocular surface is an important factor when classifying disease severity, with type III DED having progressed to the point at which chronic inflammation is sustained by irreversible mechanisms [16].

\section{APPROACHES TO DIAGNOSIS AND MONITORING OF DRY EYE DISEASE}

DED is a heterogenous condition; symptoms may be variable and inconsistent with the changes observed at the ocular surface $[5,7,13,17]$. Signs and symptoms can appear similar to those reported in cases of ocular infection or allergy [7, 13, 17]. The published TFOS DEWS II report includes criteria for diagnosis and appropriate testing recommendations, and the ODISSEY European Consensus Group has proposed a diagnostic algorithm to assist in the grading of severity as well as monitoring of ongoing disease progression $[13,18]$.

Clinical assessments should examine the production and quality of tears and identify damage at the ocular surface. Standard tests include tear film break-up time (TBUT), Schirmer's test (with/without anaesthesia) and ocular surface staining/corneal fluorescein staining (CFS; Oxford scale grade) $[5,7,18,19]$. Slit lamp examination of the eyelashes, eyelid margins and meibomian gland orifices (with expression of meibomian secretion) is also helpful in identifying MGD $[5,7,18,19]$.

Identification of ocular surface inflammation is critical in making an accurate diagnosis and grading the severity of disease [17]. Many people with DED will present with conjunctival or eyelid hyperaemia and this typically indicates the presence of inflammation at the ocular surface, although inflammation may also be 
Table 1 Consensus criteria for classification of dry eye disease developed using the nominal group technique and Delphi method [16]

\begin{tabular}{|c|c|c|}
\hline Type I & Type II & Type III \\
\hline $\begin{array}{l}\text { Sporadic/intermittent } \\
\text { disease }\end{array}$ & Recurrent/persistent disease & Chronic disease \\
\hline $\begin{array}{l}\text { Ability to re-equilibrate } \\
\text { the ocular surface }\end{array}$ & $\begin{array}{l}\text { Reduced ability to re-equilibrate the } \\
\text { ocular surface }\end{array}$ & $\begin{array}{l}\text { Chronic inability to re-equilibrate the ocular } \\
\text { surface }\end{array}$ \\
\hline $\begin{array}{l}\text { Acute/transient } \\
\text { symptoms }\end{array}$ & Frequent symptoms & Chronic symptoms \\
\hline Subclinical inflammation & $\begin{array}{l}\text { Clinically evident inflammation } \\
\text { (sustained by reversible mechanisms) }\end{array}$ & $\begin{array}{l}\text { Clinically evident and chronic inflammation } \\
\text { (sustained by irreversible mechanisms) }\end{array}$ \\
\hline $\begin{array}{l}\text { Possible epithelial } \\
\text { alterations }\end{array}$ & Evident epithelial alterations & Persistent/chronic epithelial alterations \\
\hline $\begin{array}{l}\text { Occasional alterations in } \\
\text { quality of vision }\end{array}$ & Frequent alterations in quality of vision & Frequent alterations in quality of vision \\
\hline
\end{tabular}

From Barabino et al. [16]

present in those without obvious signs of hyperaemia [17]. Osmolarity testing and identification of pro-inflammatory biomarkers such as metalloproteinase-9 (MMP-9) may be helpful in identifying evidence of ocular surface inflammation [5, 17, 20]. However, mild/moderate disease (type I or type II DED) can be overlooked during assessments with these technologies as compensatory mechanisms within the eye (e.g. increased blink rate, aqueous tear production) mask less severe disease and commercial rapid testing tools/platforms (e.g. InflammaDry) will only detect target protein at levels above a defined threshold (typically $40 \mathrm{ng} / \mathrm{ml}$ for MMP-9) $[5,17]$.

Patient-centred tools and questionnaires including the Ocular Surface Disease Index (OSDI) and Dry Eye Questionnaire (DEQ-5) support the clinician in understanding symptom severity and the impact that DED may have on the individual's daily life [18].

\section{TREATMENT OF DRY EYE}

Treatment of DED focuses on the improvement of ocular discomfort and reduction of complications $[5,13,14]$. Topical treatments, such as artificial tears/tear substitutes, are the usual first-line therapy for all types of DED alongside lid hygiene and advice on the avoidance or management of triggers [5, 13, 14]. Expert consensus group recommendations have proposed the use of new terminology to allow tear substitutes to be defined/grouped according to their effect on the ocular surface as wetting agents, multiple-action tear substitutes or ocular surface modulators [21]. Table 2 provides an overview of the properties associated with each type of agent. Conventional tear substitutes (or wetting agents) are intended to lubricate the ocular surface and replace or supplement the aqueous component of lacrimal film [21]. They do not generally target inflammation or improve ocular homeostasis [21]. Poor retention of tear substitutes at the ocular surface can limit the effectiveness of these treatments, particularly in the case of low viscosity formulations [21]. Multiple-action tear substitutes aim to improve the quality and quantity/thickness of the tear film [21]. These might include oil-inwater-based nanoemulsion formulations that lengthen residence time at the ocular surface as well as increasing the thickness and stability of 
Table 2 Consensus group proposal for tear substitute terminology and properties of each category of agent [21]

\begin{tabular}{lll}
\hline Wetting agents & Multiple-action tear substitutes & Ocular surface modulators \\
\hline $\begin{array}{l}\text { Lubricate the ocular } \\
\text { surface }\end{array}$ & $\begin{array}{c}\text { Improve quality and quantity of tear film } \\
\text { components }\end{array}$ & Polymers \\
$\begin{array}{l}\text { Limited residence } \\
\text { time }\end{array}$ & $\begin{array}{c}\text { Limited capacity to interact with ocular } \\
\text { surface epithelia }\end{array}$ & $\begin{array}{l}\text { Capacity to interact with and influence ocular } \\
\text { surface components } \\
\end{array}$ \\
& $\begin{array}{l}\text { Promote ocular surface homeostasis } \\
\text { Promote healthy cellular functioning }\end{array}$ \\
& Eventually modulate the inflammatory process \\
\hline
\end{tabular}

From Barabino et al. [21]

the tear film lipid layer (TFLL) [22]. Treatments categorised as ocular surface modulators may contain agents that support ocular surface homeostasis and the health of epithelial cells [21]. Recent data suggest that tear substitutes containing high molecular weight hyaluronan fluid, which increases viscosity and water retention, aid epithelial cell migration and healing to help in relieving more severe symptoms $[21,23]$.

Treatments that target inflammation (e.g. topical steroids) are required to address acute flare-up in response to triggers [5, 12, 13]. For recurrent or chronic dry eye (type II or type III), immunomodulatory drugs (such as ciclosporin A) have been shown to improve the signs and symptoms of long-term or chronic inflammation [5, 12, 13, 24-27]. Other treatments can include the use of therapeutic contact lenses and systemic immunosuppressive drugs [12, 21]. Surgical interventions (e.g. punctal plugs) may occasionally be used to reduce tear outflow, although such approaches are usually temporary $[5,12,21]$.

Where underlying causes of dry eye (e.g. hormone levels, contact lens use) have been identified, steps should be taken to manage and reduce exposure to triggers or appropriate specialist referral is recommended. Given the significant connection between environmental/ lifestyle factors and DED severity, discussions concerning aspects of the patient's daily routine or regular activities will support positive behavioural change (e.g. reduced smartphone usage) and the introduction of practical interventions (e.g. humidifiers) to increase the chances of treatment success [15]. Lifestyle interventions, such as advice on diet or nutritional supplements, may be appropriate. For example, fatty acids contained in fish or flaxseed are believed to enhance tear production and quality $[7,15]$. Adequate sleep, hydration and the use of protective eye wear are also important considerations for people experiencing DED symptoms [5]. Healthcare professional (HCPs) should work with individuals to understand and address the psychological impact of their condition on daily life and to discuss strategies or support services that may be available to them $[15,21]$.

\section{EVOLUTION OF DRY EYE DISEASE DURING THE COVID-19 PANDEMIC}

Research exploring patient experiences in dry eye via social media listening research prior to the start of the 2020 COVID-19 pandemic highlighted significant unmet need regarding general understanding of DED and the impact of the disease on QoL, including workplace difficulties, electronic device usage, stress and social stigma [28]. The COVID-19 pandemic has driven dramatic changes in the way that most people conduct their lives, causing many to rely on screen-based technologies to enable remote approaches to working, socialising and learning, with restricted access to face-to-face health and support services (particularly during the 
first lockdown period). Large proportions of the global population have endured multiple lockdowns, being mandated to leave home only for essential activities (e.g. food shopping, work in front-line services) and causing many to spend the majority of their time in low humidity households with limited airflow. These conditions are known to encourage exacerbations of dry eye and it would be reasonable to expect that such modifications to daily life might be accompanied by worsening or progression of DED, greater likelihood of disease onset and, subsequently, a negative associated impact on QoL [29-31].

The literature includes a vast number of studies and articles indicating that DED is likely to have been worsened during the COVID-19 pandemic period [32-36]. In addition to the ocular signs and symptoms reported among people contracting the COVID-19 virus, the lifestyle changes associated with social distancing measures and the wearing of masks have implications for ocular health [32-39]. The term "quarantine dry eye" has been proposed by Napoli et al. in their recent hypothesis paper discussing the aspects of lockdown lifestyle likely to affect ocular surface health, from environmental and behavioural factors through to diet, hydration, sleep deprivation and the psychological challenges associated with the pandemic restrictions [32]. Their article also provides some practical approaches to the management of dry eye and modifications that can be made to aspects of daily living to reduce the impact on disease severity [32]. These issues are illustrated through the results of a recent dry eye patient survey that was commissioned to gain an understanding of the potential consequences associated with the first COVID-19 lockdown period in Europe among people with DED. The results of this survey have not previously been shared but highlight some of the key issues affecting people living with DED during the pandemic and may be of value for clinicians to keep in mind when conducting patient reviews. The survey included 502 adults (aged 18-75 years) with DED and examined common behavioural and lifestyle changes that occurred during the first wave of the pandemic (March 2020-September 2020), and assessed their impact on the severity dry eye symptoms experienced. The 15-min online survey, comprising 10 screening questions followed by 21 multiple choice questions, was completed during July 2020 by 100 participants living in Germany, Spain and the UK, and 101 in both France and Italy. The questionnaire was divided into three sections: the impact of COVID-19 on daily life, the ways in which dry eye had affected life in recent weeks, interactions with healthcare services and satisfaction with treatments. The survey outputs provide an overview of the challenges faced by people living with dry eye during the pandemic and the key aspects of the disease that respondents found most bothersome. As a result of the design and brief nature of the survey, further in-depth analysis is not possible, but this information supports the case for future studies to understand the evolving concerns and perspectives of patients with dry eye so that clinicians may have a more holistic understanding of their patients' needs.

Overall, $60 \%$ of respondents were female and the majority (69\%) were above 40 years of age. Seventy per cent had been diagnosed for more than 1 year at the time of the survey and ophthalmologists were the most frequent type of HCP responsible for diagnosing dry eye (69\%). DED had been identified by a general practitioner (GP), pharmacist or optician in 19\% of survey participants and the remainder had selfdiagnosed. Ideally, patients with persistent dry eye symptoms should be referred to specialist ophthalmology services to ensure accurate diagnosis and optimal treatment of this longterm condition [7]. Nine per cent had developed DED since the start of the lockdown period. All participants used regular dry eye treatments to relieve their symptoms, with $68 \%$ using prescription therapies and OTC medicines being purchased by $58 \%$ of respondents.

Most participants (72\%) said that dry eye had negatively impacted their life during the pandemic and the emotional consequences were evident among this group, with around onethird reporting that DED had caused stress (36\%), irritability (36\%), exhaustion (34\%) and frustration (32\%) (Fig. 1). Increased screen time (59\%), higher stress levels (50\%) and lack of sleep or disrupted sleep (43\%) were the most 


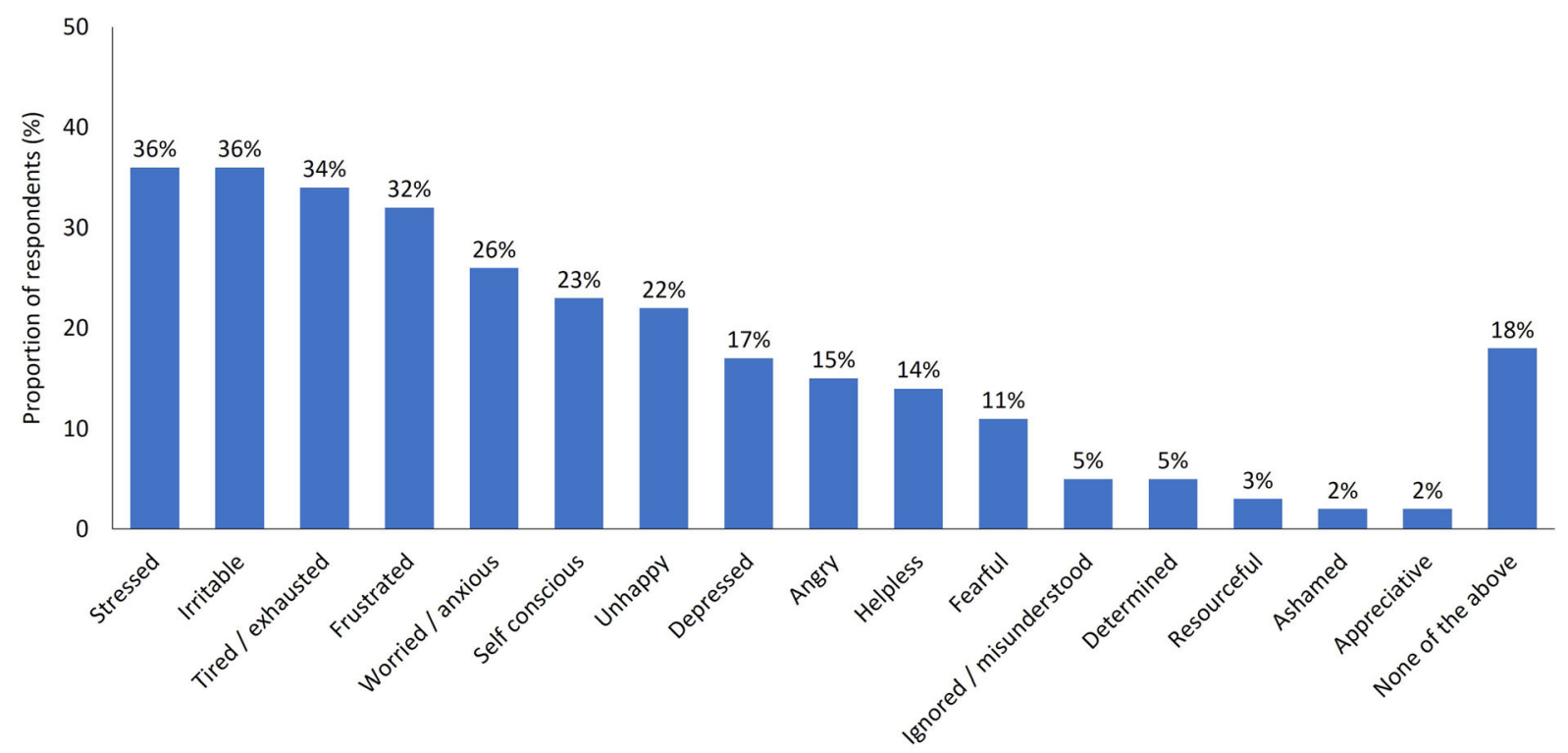

Fig. 1 Survey responses regarding the emotional impact of dry eye during the COVID-19 pandemic. Response to the question: Please tell us if you have felt any of the below emotions as a direct result of your dry eyes in the past

frequently cited reasons for problematic or worsening symptoms of DED (Fig. 2).

The majority of participants (65\%) indicated that time spent using screen-based technologies was increased by at least $29 \%$ during the lockdown period. Those who reported increased screen time were significantly more likely to experience worsening of symptoms compared with those who did not $(p<0.05$ [comparison conducted using a standard $t$ test]). The symptoms most frequently reported to be exacerbated during the pandemic were tired eyes $(84 \%)$, increased dryness or grittiness $(67 \%)$ and worsening of vision/blurred vision (55\%). The use of digital and screen-based technologies is known to be associated symptoms of digital eye strain (DES), which include dry eye and ocular discomfort, and blink rate is estimated to be reduced from around 18 blinks per minute to three or four [33, 40-42]. A recent survey of teleworkers also suggested that the number of hours spent using a visual display terminal was a relevant factor in increasing eye strain a DED prevalence during the pandemic period [33]. The intensity or force of blinking is lowered during screen use and incomplete blinking has
4 months, since the start of the COVID-19 crisis. Participants were able to provide multiple responses to this question. Base: Total $(n=502)$

been reported, in which the eyelid does not fully cover the corneal surface [41]. Blinking is a critical element in replenishing and maintaining the integrity of the tear film, particularly in dry environments when evaporation of tears at the ocular surface will be greater [41].

Dry eye affected productivity during the lockdown, when many people were dependent on screen-based devices to continue their work; $15 \%$ said that DED had reduced their ability to work or slowed them down and 10\% indicated that they were unable to work because of their symptoms. In addition, $8 \%$ believed that DED had negatively affected them financially. This may have been as a consequence of reduced ability to function effectively at work or because of the costs of purchasing OTC therapies for symptom relief. Around half of respondents sought treatment for DED from a pharmacy, both prior to (47\%) and during (53\%) the pandemic.

Despite feeling that they needed to see a physician concerning their symptoms, $62 \%$ did not consult a clinician for treatment and there was a significant increase in the number who did not collect their medication during the 


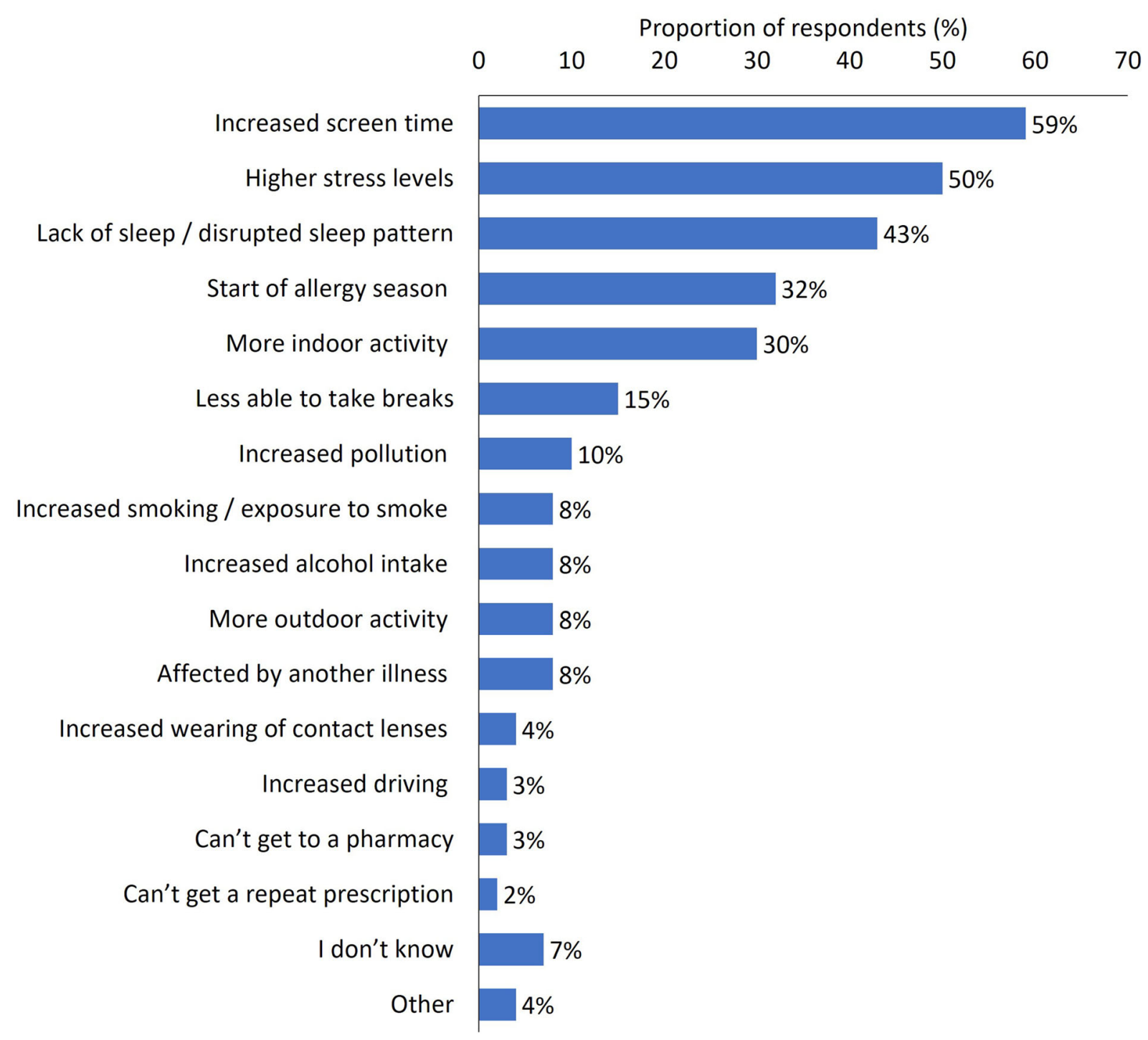

Fig. 2 Reasons for problematic symptoms or worsening of dry eye symptoms during the COVID-19 pandemic. Response to the question: Why do you think your dry eyes have remained a problem/become worse in the last 4 months, since the start of the COVID-19 crisis?

lockdown compared with the period prior to pandemic $(p<0.05)$. Reasons for not seeing a clinician were fear of catching COVID-19 (35\%) and a desire to lessen the burden on health services (27\%). In addition, $21 \%$ were unable to obtain an appointment because of reduced provision of face-to-face services. However, around half of all respondents (47\%) said that they would like an HCP to recommend or
Participants were able to provide multiple responses to this question. Base: All respondents who indicated that dry eye had become worse, or still caused problems $(n=261)$

prescribe a more effective treatment and 32\% felt that advice on lifestyle changes to minimise worsening of their symptoms would be of value. A practical solution to healthcare access issues might be the application of virtual clinics, delivered online or via the telephone (if appropriate), which have shown promise in glaucoma management and could remove existing and/or perceived barriers to services while allowing 
patients to be effectively triaged so that the most severe cases are prioritised to attend appointments within the ophthalmology clinic [43]. Access issues may be complicated further in the future by emerging reports of ocular manifestations of COVID-19, predominantly conjunctivitis, and debate continues among clinicians regarding the potential for transmission of the virus via the ocular surface $[36,44-47]$. As discussed by Napoli et al. transmission of COVID-19 occurs through the binding of the viral spike protein to angiotensinconverting enzyme 2 (ACE2) receptors and priming of the viral spike via transmembrane serine protease 2 (TMPRSS2) [39]. ACE2 receptors and TMPRSS2 are both prevalent in the eye (as they are throughout the body) [39]. It is possible that the viral load may be more readily retained at the ocular surface in people with dry eye (leading to conjunctivitis) as dispersion via normal tearing mechanisms to the respiratory/ digestive tract is less effective [39]. Dry eye is among the most commonly reported COVIDassociated ocular symptoms alongside tearing, itching, eye pain and discharge [39, 47]. A number of topical ophthalmic therapies, including some commonly used for the treatment of dry eye, contain agents that have shown some antiviral activity but further studies would be needed to understand how such compounds could protect the ocular surface from COVID-19 infection [48, 49]. Although evidence suggests that a low risk of COVID transmission via the tears exists, ophthalmologists, technicians and other HCPs conducting close contact work with patients must take care to wear personal protective equipment, including protective goggles or face shield and breath shields for slit lamp procedures, to reduce exposure to droplet infection [39, 45-47]. HCPs working in ophthalmology settings would benefit from additional guidance and international consensus regarding best practice in ocular procedures and protection against cross-infection risk, for both the patient and the clinician [50-59]. These factors have major implications for ophthalmologists in terms of the practicalities of patient interactions and procedures, as well as increased training burden and issues that may arise from a regulatory/legal perspective [50-59].

\section{CONCLUSIONS AND IMPLICATIONS FOR CLINICAL PRACTICE}

DED remains a complex and multifactorial condition that can be challenging to accurately diagnose and represents a growing health, QoL and financial burden. However, our evolving understanding of the pathogenesis of disease and newer definitions of the types of DED that are typically seen in clinical practice may provide opportunities for more individualised approaches to treatment $[16,21]$. While people presenting with type I DED may benefit from aqueous or multiple-action artificial tears alone, recurrent or chronic dry eye cases (type II and type III) are likely to require more aggressive therapeutic approaches that aim to reduce inflammation, restore ocular surface homeostasis and promote effective epithelial healing $[16,21]$.

The use of screen-based technologies has become an integral part of modern life, with mobile devices and computers being critical for many work/business, educational and social activities [40-42]. DES is increasingly recognised as an underlying cause of DED and, while many cases of DED are connected with aging and chronic diseases, evidence suggests that DES and dry eye are present among increasingly younger populations and could be connected with the use of smartphones or other digital technologies that causes changes in blink rate and force [16, 40-42, 60-62]. The results of our online survey emphasise the impact of increased screen time on symptom severity and the potential influence of factors such as sleep and stress. Further studies would be of interest to understand how these aspects affect the type of dry eye seen in clinical practice and whether these individuals would be defined as having type I, type II or type II disease [16]. The emotional impact of DED must not be underestimated; our survey revealed that 4 out of 5 people with dry eye felt that their condition increased the severity of mental health and QoL 
factors such as stress, anxiety, depression, unhappiness and fear. The psychological impact of dry eye has been recognised in the literature and in clinical practice over many years and there is a need for greater awareness of these issues, with mechanisms in place to provide additional support for those who require it $[7,9,10,15]$.

Survey respondents said that they would like to be prescribed more effective treatments, although the majority did not consult an HCP and more than half were relying on OTC therapies for symptom relief, because of concerns around the risk of catching COVID-19, limited access to healthcare appointments and a desire to reduce the strain on services. These individuals may have benefitted from access to an HCP via an online or telephone consultation. The survey results also illustrate the value that people with DED place upon HCP advice regarding strategies and lifestyle adjustments to minimise symptoms.

The future of dry eye management may benefit from a more holistic approach, in which ophthalmologists and other HCPs are able to help patients take practical steps to reduce exposure to triggers (e.g. taking regular screen breaks) associated with worsening inflammation or symptoms, manage the psychological aspects of their disease and match therapeutic interventions to the appropriate type of DED to increase the chances of long-term treatment success term.

\section{ACKNOWLEDGEMENTS}

Funding. The COVID-19 dry eye survey and associated analysis was conducted by Wordbird Limited on behalf of Santen. Funding for Rapid Service was also provided by Santen.

Medical Writing Assistance. Medical writing services were provided on behalf of the author by Rebecca Down at Copperfox Communications Limited. Support for this assistance was funded by Santen.
Authorship. All named authors meet the International Committee of Medical Journal Editors (ICMJE) criteria for authorship for this article, take responsibility for the integrity of the work as a whole, and have given their approval for this version to be published.

Authorship Contributions. Professor Stefano Barabino was responsible for the conceptualisation, data identification, editing and critical review of the manuscript.

Disclosures. Professor Stefano Barabino has no relevant financial disclosures.

Compliance with Ethics Guidelines. This article is based on previously conducted studies and does not contain any new clinical studies with human participants or animals performed by the author. The author would like to thank Santen for providing access to the survey data as well as the patients with dry eye who participated in the online survey and reported their experience of DED during the COVID-19 pandemic.

Data Availability. Data sharing is not applicable to the majority of this review article as no datasets were generated or analyzed. However, patient survey data discussed in the final section are available from the corresponding author upon reasonable request.

Open Access. This article is licensed under a Creative Commons Attribution-NonCommercial 4.0 International License, which permits any non-commercial use, sharing, adaptation, distribution and reproduction in any medium or format, as long as you give appropriate credit to the original author(s) and the source, provide a link to the Creative Commons licence, and indicate if changes were made. The images or other third party material in this article are included in the article's Creative Commons licence, unless indicated otherwise in a credit line to the material. If material is not included in the article's Creative Commons licence and your intended use is not permitted by statutory regulation or exceeds the permitted use, you will need to obtain permission directly from the 
copyright holder. To view a copy of this licence, visit http://creativecommons.org/licenses/by$\mathrm{nc} / 4.0 /$.

\section{REFERENCES}

1. Stapleton F, Alves M, Bunya VY, et al. TFOS DEWS II epidemiology report. Ocul Surf. 2017;15:334-65.

2. Craig JP, Nichols KK, Akpek EK, et al. TFOS DEWS II definition and classification report. Ocul Surf. 2017; 15:276-83.

3. Nelson JD, Craig JP, Akpek EK, et al. TFOS DEWS II Introduction. Ocul Surf. 2017;15:269-75.

4. Chou A, Gonzales JA, Daniels TE, Criswell LA, Shiboski SC, Shiboski CH. Health-related quality of life and depression among participants in the Sjögren's International Collaborative Clinical Alliance registry. RMD Open. 2017;3(2):e000495.

5. Clayton JA. Dry eye. N Engl J Med. 2018;378: 2212-23.

6. McDonald M, Patel DA, Keith MS, Snedecor SJ. Economic and humanistic burden of dry eye disease in Europe, North America, and Asia: a systematic literature review. Ocul Surf. 2016;14(2):144-67.

7. Messmer EM. The pathophysiology, diagnosis, and treatment of dry eye disease. Dtsch Arztebl Int. 2015;112(5):71-81.

8. Wang MTM, Muntz A, Mamidi B, Wolffsohn JS, Craig JP. Modifiable lifestyle risk factors for dry eye disease. Cont Lens Anterior Eye. 2021:101409.

9. Li M, Gong L, Chapin WJ, et al. Assessment of vision-related quality of life in dry eye patients. Invest Ophthalmol Vis Sci. 2012;53:5722-7.

10. Uchino M, Schaumberg DA. Dry eye disease: Impact on quality of life and vision. Curr Ophthalmol Rep. 2014;1:51-7.

11. Rolando M, Refojo MF, Kenyon KR. Tear water evaporation and eye surface diseases. Ophthalmologica. 1985;190:147-9.

12. Baudouin C, Messmer EM, Aragona P, et al. Revisiting the vicious circle of dry eye disease: a focus on the pathophysiology of meibomian gland dysfunction. Br J Ophthalmol. 2016;100:300-6.

13. Baudouin C, Irkeç M, Messmer EM, et al. Clinical impact of inflammation in dry eye disease: proceedings of the ODISSEY group meeting. Acta Ophthalmol. 2018;96(2):111-9.

14. Jones L, Downie LE, Korb D, et al. TFOS DEWS II management and therapy report. Ocul Surf. 2017;15(3):575-628.

15. Donthineni PR, Shanbhag SS, Basu S. An evidencebased strategic approach to prevention and treatment of dry eye disease, a modern global epidemic. Healthcare (Basel). 2021;9(1):89.

16. Barabino S, Aragona P, di Zazzo A, Rolando M, Società Italiana di Dacriologia e Superficie Oculare. Updated definition and classification of dry eye disease: renewed proposals using the nominal group and Delphi techniques. Eur J Ophthalmol. 2021;31(1):42-8.

17. Pleyer U, Geerling G, Schrader S, Jacobi C, Kimmich F, Messmer E. Wenn Tränenersatzmittel nicht mehr ausreichen: die Bedeutung von Entzündungsprozessen beim Trockenen Auge. Praktische Aspekte einer antientzündlichen Therapie des Trockenen Auges [If Artificial Tears Aren't Enough. The Importance of Inflammatory Processes in Dry Eye Disease. Practical Aspects of an Anti-Inflammatory Therapy of Dry Eye Disease]. Klin Monbl Augenheilkd. 2020;237(5):655-68.

18. Wolffsohn JS, Arita R, Chalmers R, et al. TFOS DEWS II diagnostic methodology report. Ocul Surf. 2017;15:539-74.

19. Verjee MA, Brissette AR, Starr CE. Dry eye disease: early recognition with guidance on management and treatment for primary care family physicians. Ophthalmol Ther. 2020;9(4):877-88.

20. Hessen M. All about osmolarity. Review of Optometry. 2018. https://www.reviewofoptometry. com/article/all-about-osmolarity. Accessed February 2021 .

21. Barabino S, Benitez-Del-Castillo JM, Fuchsluger T, et al. Dry eye disease treatment: the role of tear substitutes, their future, and an updated classification. Eur Rev Med Pharmacol Sci. 2020;24(17): 8642-52.

22. Garrigue JS, Amrane M, Faure MO, Holopainen JM, Tong L. Relevance of lipid-based products in the management of dry eye disease. J Ocul Pharmacol Ther. 2017;33(9):647-61.

23. van Setten GB, Baudouin C, Horwath-Winter J, et al. The HYLAN M study: efficacy of $0.15 \%$ high molecular weight hyaluronan fluid in the treatment of severe dry eye disease in a multicenter randomized trial. J Clin Med. 2020;9:3536. 
24. Baudouin C, de la Maza MS, Amrane M, et al. Oneyear efficacy and safety of $0.1 \%$ cyclosporine A cationic emulsion in the treatment of severe dry eye disease. Eur J Ophthalmol. 2017;27:678-85.

25. Leonardi A, Messmer EM, Labetoulle M, et al. Efficacy and safety of $0.1 \%$ ciclosporin A cationic emulsion in dry eye disease: a pooled analysis of two double-masked, randomised, vehicle-controlled phase III clinical studies. Br J Ophthalmol. 2019;103:125-31.

26. Leonardi A, Flamion B, Baudouin C. Keratitis in Dry Eye Disease and Topical Ciclosporin A. Ocul Immunol Inflamm. 2017;25(4):577-86.

27. Leonardi A, Van Setten G, Amrane M, et al. Efficacy and safety of $0.1 \%$ cyclosporine A cationic emulsion in the treatment of severe dry eye disease: a multicenter randomized trial. Eur J Ophthalmol. 2016;26(4):287-96.

28. Cook N, Mullins A, Gautam R, Medi S, Prince C, Tyagi N, Kommineni J. Evaluating patient experiences in dry eye disease through social media listening research. Ophthalmol Ther. 2019;8(3): 407-20.

29. Fernández I, López-Miguel A, Enríquez-de-Salamanca A, et al. Response profiles to a controlled adverse desiccating environment based on clinical and tear molecule changes. Ocul Surf. 2019;17(3): 502-15.

30. López-Miguel A, Tesón M, Martín-Montañez V, et al. Dry eye exacerbation in patients exposed to desiccating stress under controlled environmental conditions. Am J Ophthalmol. 2014;157(4):788798.e2.

31. Alex A, Edwards A, Hays JD, et al. Factors predicting the ocular surface response to desiccating environmental stress. Invest Ophthalmol Vis Sci. 2013;54(5):3325-32.

32. Napoli PE, Nioi M, Fossarello M. The, "quarantine dry eye": the lockdown for coronavirus disease 2019 and its implications for ocular surface health. Risk Manag Healthc Policy. 2021;14:1629-36.

33. Salinas-Toro D, Cartes C, Segovia C, et al. High frequency of digital eye strain and dry eye disease in teleworkers during the coronavirus disease (2019) pandemic. Int J Occup Saf Ergon. 2021;2021:1-27.

34. Boccardo L. Self-reported symptoms of mask-associated dry eye: a survey study of 3,605 people. Cont Lens Anterior Eye. 2021;2021:101408.

35. Pandey SK, Sharma V. Mask-associated dry eye disease and dry eye due to prolonged screen time: are we heading towards a new dry eye epidemic during the COVID-19 era? Indian J Ophthalmol. 2021;69(2):448-9.

36. Koh S, Rhee MK. COVID-19 and dry eye. Eye Contact Lens. 2021;47(6):317-22.

37. Rokohl AC, Grajewski RS, Matos PAW, Kopecky A, Heindl LM, Cursiefen C. Ocular involvement in COVID-19: conjunctivitis and more. Klin Monbl Augenheilkd. 2021;238(5):555-60.

38. Nasiri N, Sharifi H, Bazrafshan A, Noori A, Karamouzian M, Sharifi A. Ocular manifestations of COVID-19: a systematic review and meta-analysis. J Ophthalmic Vis Res. 2021;16(1):103-12.

39. Napoli PE, Nioi M, d'Aloja E, Fossarello M. The ocular surface and the coronavirus disease 2019: does a dual "ocular route" exist? J Clin Med. 2020;9(5):1269.

40. Robbins T, Hudson S, Ray P, et al. COVID-19: a new digital dawn? Digit Health. 2020;6: 2055207620920083.

41. Sheppard AL, Wolffsohn JS. Digital eye strain: prevalence, measurement and amelioration. BMJ Open Ophthalmol. 2018;3(1):e000146.

42. Patel S, Henderson R, Bradley L, Galloway B, Hunter L. Effect of visual display unit use on blink rate and tear stability. Optom Vis Sci. 1991;68(11):888-92.

43. Spackman W, Waqar S, Booth A. Patient satisfaction with the virtual glaucoma clinic. Eye (Lond). 2020. https://doi.org/10.1038/s41433-020-0946-5.

44. Scalinci SZ, Trovato BE. Conjunctivitis can be the only presenting sign and symptom of COVID-19. IDCases. 2020;20:e00774.

45. Almazroa A, Alamri S, Alabdulkader B, Alkozi H, Khan A, Alghamdi W. Ocular transmission and manifestation for coronavirus disease: a systematic review. Int Health. 2021;27:28.

46. Hu K, Patel J, Swiston C, Patel BC. Ophthalmic manifestations of coronavirus (COVID-19). 2021 May 19. Treasure Island (FL): StatPearls; 2021 Jan. PMID: 32310553.

47. Dockery DM, Rowe SG, Murphy MA, Krzystolik MG The ocular manifestations and transmission of COVID-19: recommendations for prevention. J Emerg Med. 2020;59(1):137-40.

48. Napoli PE, Mangoni L, Gentile P, Braghiroli M, Fossarello M. A panel of broad-spectrum antivirals in topical ophthalmic medications from the drug repurposing approach during and after the coronavirus disease 2019 era. J Clin Med. 2020;9(8):2441. 
49. Shetty R, Lalgudi VG, Khamar P, et al. Potential ocular and systemic COVID-19 prophylaxis approaches for healthcare professionals. Indian J Ophthalmol. 2020;68(7):1349-56.

50. Napoli PE, Nioi M, d'Aloja E, Fossarello M. Safety recommendations and medical liability in ocular surgery during the COVID-19 pandemic: an unsolved dilemma. J Clin Med. 2020;9(5):1403.

51. Almazroa A. Sustainability of ophthalmology practice and training during and post the pandemic of coronavirus (COVID-19): a review. Clin Ophthalmol. 2021;15:2355-65.

52. Wong TY, Bandello F. Academic ophthalmology during and after the COVID-19 pandemic. Ophthalmology. 2020;127(8):e51-2.

53. Lim LW, Yip LW, Tay HW, et al. Sustainable practice of ophthalmology during COVID-19: challenges and solutions. Graefes Arch Clin Exp Ophthalmol. 2020;258(7):1427-36.

54. Safadi K, Kruger JM, Chowers I, et al. Ophthalmology practice during the COVID-19 pandemic. BMJ Open Ophthalmol. 2020;5(1):e000487.

55. Lai THT, Tang EWH, Chau SKY, Fung KSC, Li KKW. Stepping up infection control measures in ophthalmology during the novel coronavirus outbreak: an experience from Hong Kong. Graefes Arch Clin Exp Ophthalmol. 2020;258(5):1049-55.
56. Olivia Li JP, Shantha J, Wong TY, et al. Preparedness among ophthalmologists: during and beyond the COVID-19 pandemic. Ophthalmology. 2020;127(5):569-72.

57. Sadhu S, Agrawal R, Pyare R, et al. COVID-19: limiting the risks for eye care professionals. Ocul Immunol Inflamm. 2020;28(5):714-20.

58. Romano MR, Montericcio A, Montalbano C, et al. Facing COVID-19 in ophthalmology department. Curr Eye Res. 2020;45(6):653-8.

59. Ferrara M, Romano V, Steel DH, et al. Reshaping ophthalmology training after COVID-19 pandemic. Eye (Lond). 2020;34(11):2089-97.

60. de Paiva CS. Effects of aging in dry eye. Int Ophthalmol Clin. 2017;57(2):47-64.

61. Survey of Health, Age and Retirement in Europe (SHARE). The retirement age rises. Pension reforms in Europe have raised the realized retirement age. http://www.share-project.org/press-news/shareresearch-findings/new-scientific-findings/theretirement-age-rises.html. Accessed February 2021.

62. Golebiowski B, Long J, Harrison K, Lee A, ChidiEgboka N, Asper L. Smartphone use and effects on tear film, blinking and binocular vision. Curr Eye Res. 2020;45(4):428-34. 